\title{
Individualized Isonatremic and Hyponatremic Dialysate Improves Blood Pressure in Patients with Intradialytic Hypertension: A Prospective Cross-Over Study with 24-h Ambulatory Blood Pressure Monitoring
}

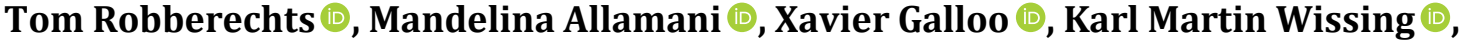 \\ Patricia Van Der Niepen* (1)
}

Department of Nephrology and Hypertension, Universitair Ziekenhuis Brussel, VUB, Brussels, Belgium

Email: *patricia.vanderniepen@uzbrussel.be

How to cite this paper: Robberechts, T., Allamani, M., Galloo, X., Wissing, K.M. and Van Der Niepen, P. (2020) Individualized Isonatremic and Hyponatremic Dialysate Improves Blood Pressure in Patients with Intradialytic Hypertension: A Prospective Cross-Over Study with 24-h Ambulatory Blood Pressure Monitoring. Open Journal of Nephrology, 10, 144-157.

https://doi.org/10.4236/ojneph.2020.102015

Received: May 8, 2020

Accepted: June 20, 2020

Published: June 23, 2020

Copyright $\odot 2020$ by author(s) and Scientific Research Publishing Inc. This work is licensed under the Creative Commons Attribution International License (CC BY 4.0).

http://creativecommons.org/licenses/by/4.0/ (c) (i) Open Access

\section{Abstract}

Background. Intradialytic hypertension, a paradoxical rise in systolic blood pressure from pre- to postdialysis, is a poorly understood and difficult-to-treat phenomenon. We examined the effects of individually adjusted isonatremic and hyponatremic dialysate on intradialytic and interdialytic blood pressure in patients with intradialytic hypertension. Methods. We enrolled 11 patients with intradialytic hypertension in a prospective randomized cross-over study, with 4 treatment periods of different dialysate sodium concentrations. Period 1 (run-in) and 3 (wash-out) were standardized at $140 \mathrm{mEq} / \mathrm{L}$; period 2 and 4 with iso- or hyponatremic sodium dialysate. Blood pressure was recorded each dialysis session, and 24-hour ambulatory blood pressure monitoring was performed at the end of each treatment period. Results. Isonatremic and hyponatremic dialysate were associated with significantly lower pre- and post-dialysis blood pressure as compared to baseline $140 \mathrm{mEq} / \mathrm{L}$ dialysate (predialysis $148.3 \pm 24.7 / 67.7 \pm 12.0$ and $144.4 \pm 16.5 / 68.8 \pm 13.3$ vs. $158.0 \pm 18.3 / 75.6 \pm$ $11.4 \mathrm{mmHg}$, resp $\mathrm{p}=0.04$ and 0.007 for systolic and $\mathrm{p}=0.004$ and 0.04 for diastolic blood pressure; postdialysis $154.2 \pm 25.5 / 76.6 \pm 14.1$ and $142.5 \pm$ $20.7 / 73.0 \pm 12.9$ vs. $159.1 \pm 21.6 / 80.3 \pm 12.1 \mathrm{mmHg}$, resp NS and $\mathrm{p}=0.01$ for systolic and NS and $\mathrm{p}=0.04$ for diastolic blood pressure). Postdialysis and 24 $\mathrm{h}$ systolic blood pressure tended to be lower with hyponatremic compared to isonatremic dialysate. Conclusion. Individually tailoring dialysate sodium concentration, based on the sodium set-point of each patient, resulted in a lower pre- and post-dialysis blood pressure in patients with intradialytic 
hypertension. $24 \mathrm{~h}$ blood pressure values tended to be lower as well with hyponatremic dialysate.

\section{Keywords}

Intradialytic Hypertension, Ambulatory Blood Pressure Monitoring, Dialysate Sodium Concentration

\section{Introduction}

Intradialytic hypertension (IDH), often defined as a paradoxical rise in systolic blood pressure (BP) of $\geq 10 \mathrm{mmHg}$ from pre- to postdialysis, is a frequent but still incompletely understood phenomenon. It is a risk factor for hospitalization and death in hemodialysis (HD) patients [1]. Two main mechanisms have been proposed in its pathophysiology [2]. On the one hand, bioimpedance spectroscopy studies show extracellular volume overload in patients with IDH [3]. On the other hand, a higher vascular resistance during dialysis may explain the rise in BP [3] [4]. Endothelial cell dysfunction, sympathetic nervous system or renin-angiotensin-aldosterone system activation, and dialysis-specific factors such as dialysate composition have all been suggested as possible causes of the increased vascular resistance, with varying degree of evidence [2].

Dialysate sodium concentration $(\mathrm{DNa})$ plays a major role in sodium balance in end stage renal disease [5]. Since patients with IDH typically present lower ultrafiltration rates [6], sodium removal during dialysis will depend more on diffusion than on convection. This emphasizes the role of $\mathrm{DNa}$ in the net sodium transfer. While lower DNa enhances sodium removal from the plasma and decreases the sodium load, a high $\mathrm{DNa}$ results in the opposite. A high dialysate-to-serum sodium gradient might lead to a higher BP by volume overload [7] or by non-volume related effects, as endothelial cell dysfunction [8], increased central sympathetic outflow [9], or cardiomyocyte and vascular smooth muscle cell hypertrophy [10].

An association between intradialytic sodium gradient and BP has been observed in patients with IDH [11]: the more positive the gradient, the more positive the intradialytic BP change. An interventional trial comparing low to high $\mathrm{DNa}$ ( $5 \mathrm{mEq} / \mathrm{L}$ below or above serum sodium) in patients with IDH showed lower systolic BP and attenuated intradialytic BP change [12]. However, this study was limited by relatively short follow up and did not assess interdialytic BP.

To our knowledge, no interventional trial with long term follow up has investigated the effect of dialysate sodium concentration on both intradialytic BP and interdialytic BP (assessed by 24 hour ambulatory monitoring or $24 \mathrm{~h} \mathrm{ABPM}$ ) in IDH.

We designed a prospective randomized cross-over study to investigate the effect of individualized DNA on intradialytic and interdialytic blood pressure in 
patients with intradialytic hypertension.

\section{Methods}

\subsection{Study Objectives}

Our primary objective was to evaluate the effect of isonatremic (matching serum and dialysate sodium concentrations) and hyponatremic dialysate (lowering dialysate sodium below serum sodium concentrations) on intradialytic and interdialytic BP in patients known with IDH. Furthermore, the effects on serum sodium and safety profile were evaluated.

We hypothesized that, compared to standard dialysate, iso- and hyponatremic dialysate would induce lower intra- and interdialytic BP, with the most pronounced effect for hyponatremic dialysate.

\subsection{Study Patients}

Patients, aged 18 years or older, in chronic HD for $\geq 3$ months and known with IDH, were eligible. Study participants needed to present an increase in pre- to post-HD systolic BP of $\geq 10 \mathrm{mmHg}$ during at least 4 out of 6 consecutive dialysis sessions at the moment of screening. They needed to be on a stable dose of antihypertensive drugs (if applicable), without clinical signs of fluid overload. Patients with a recent cardiovascular or cerebral event, a left ventricular ejection fraction below 30\%, a debilitating illness, an expected life expectancy below 6 months, a dysfunctional AV fistula or catheter, or a low dialysis efficacy (defined as $\mathrm{Kt} / \mathrm{V}<1.3$ ) were excluded [13]. Pregnancy, intradialytic hypotension, uncontrolled hypertension (average pre-HD BP > 200/110 $\mathrm{mmHg}$ ), uncontrolled diabetes mellitus, impossibility to measure BP in a standardized way, known low compliance, and simultaneous participation in other investigational studies, or inability to provide written informed consent and/or to comply with study procedures were additional exclusion criteria.

\subsection{Study Design and Interventions}

Prospective randomized single-blind cross-over study comparing the effects of hyponatremic and isonatremic with standard sodium dialysate on BP was conducted from 17th October 2012, with all study procedures completed by 13th March 2013. The study consisted of 4 phases of 4 weeks each.

\section{1) Dialysis prescription}

All patients received thrice-weekly HD, with dialysis duration of 3 - 4 hours. Dialysate sodium concentrations were set using the dialysis device set up tool, based on dialysate conductivity measurement. Except for $\mathrm{DNa}$, the dialysis prescription remained constant; no change in dry weight or in antihypertensive treatment was allowed.

After enrollment, patients were initially dialyzed with a standard DNa of 140 $\mathrm{mEq} / \mathrm{L}$ during 4 weeks. During this "run-in phase", pre-HD serum sodium concentration was measured weekly on midweek dialysis sessions to determine the 
individual average serum sodium concentration or "individual sodium set point" [14].

Subsequently, patients were randomized to a 4-week treatment on individualized isonatremic or hyponatremic dialysate. All patients were randomly assigned by concealed allocation in a 1:1 fashion.

Isonatremic dialysate was defined as a $\mathrm{DNa}$ equal to the previously calculated individual sodium set point; hyponatremic dialysate as a $\mathrm{DNa} 4 \mathrm{mEq} / \mathrm{L}$ below this set point. Dialysate sodium concentrations lower than the inferior limit of normal plasma levels were avoided.

This period was followed by a 4-week wash-out period, with a $\mathrm{DNa}$ of 140 $\mathrm{mEq} / \mathrm{l}$. Finally, patients were crossed over to an individualized hyponatremic or isonatremic dialysate for another 4 weeks (Figure 1).

Each study period consists of 4 weeks; with $24 \mathrm{~h}$ ambulatory blood pressure monitoring at midweek of the $4^{\text {th }}$ week.

\section{2) Blood pressure and 24-hour ambulatory blood pressure monitoring}

Blood pressure was measured each dialysis session, with an oscillometric automated sphygmomanometer (Colin ${ }^{\circledR}$ BP module K23564001), prior to needle insertion, and subsequently every 30 minutes until conclusion of session.

During the 4th week of every study period, an interdialytic $24 \mathrm{~h} \mathrm{ABPM}$ was performed at midweek using Spacelabs Medical ${ }^{\circ} 90217$ and 90217A monitors. The cuff was placed around the non-dominant or around the non-access upper arm, by one of the investigators or trained nurses. The device was turned on immediately after HD. Patients were instructed to continue normal daily life activities, diet and treatment. Blood pressure was measured every 15 minutes during day time (6:00 am until 10:00 pm) and every 30 minutes during nighttime. The device was removed after $24 \mathrm{~h}$ of monitoring. The actual sleeping and wakening times were recorded and used to determine real day and night BP.

\section{3) Blood sampling}

Blood samples were taken at the end of each study period, through the arterial port of the vascular access. Analyses included sodium, potassium, calcium, blood urea nitrogen (BUN), hematocrit (Hct), glucose, albumin, brain natriuretic peptide (NT-proBNP), renin, aldosterone, norepinephrine, epinephrine and dopamine, before and at the end of dialysis.

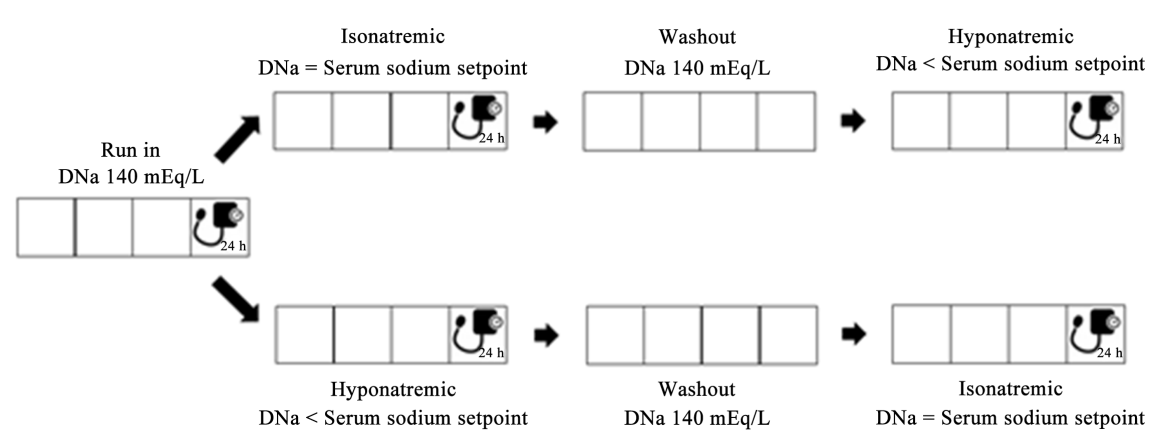

Figure 1. Schematic schedule of the study cross-over design. 
Serum sodium concentration was measured through direct potentiometry (Ortho Clinical Diagnostics, UK). All analyses were performed at the local laboratory.

\section{4) Recording of adverse events}

Adverse events such as intradialytic hypotension (defined as a decrease in SBP of $\geq 20 \mathrm{mmHg}$ or in MAP of $\geq 10 \mathrm{mmHg}$, combined with clinical symptoms, requiring assistance of a nurse), headache, cramps, nausea and vomiting were registered. Death, hospitalization or prolonged hospitalization due to study procedures were listed as serious adverse events.

\subsection{Statistical Analysis}

Assuming a $10 \pm 10 \mathrm{mmHg}$ difference in change in intradialytic systolic BP between treatments with standard compared to hyponatremic or isonatremic dialysate, 11 patients were needed in a pairwise crossover design to provide $90 \%$ power to detect this difference with $\alpha=0.05$. Continuous variables were summarized as mean \pm standard deviation or median with interquartile range. Categorical variables were expressed as proportions. Comparisons between study phases were performed using t-tests. $\mathrm{P}<0.05$ was considered to be statistically significant. All statistical analyses were performed using STATVIEW, version 5.0.1 (SAS Institute Inc.).

The study was approved by the ethics committee of the University Hospital of Brussels (approval number BUN 143201215107). All procedures were in accordance with the Declaration of Helsinki and principles of Good Clinical Practice. All participants provided written informed consent before inclusion.

\section{Results}

Thirteen out of 109 patients were found eligible for the study; two patients refused participation, 11 were enrolled and completed the study. Baseline characteristics are shown in Table 1. Dry weight and the number of antihypertensive drugs per patient were not changed during the study period as per protocol.

\subsection{Intradialytic Blood Pressure}

Both isonatremic and hyponatremic treatment were associated with significantly lower pre- and post-dialysis BP as compared to baseline $140 \mathrm{mEq} / \mathrm{L}$ dialysate (Table 2). The lowest BPs were observed with hyponatremic dialysate. At week 4 of hyponatremic treatment, predialysis systolic BP was reduced by 13.6 (95\% CI -22.5 to -4.7$) \mathrm{mmHg}$, as compared to values at run-in phase. Predialysis diastolic BP decreased by 6.8 (95\% CI -13.0 to -0.5$) \mathrm{mmHg}$. No significant difference in BP between isonatremic and hyponatremic dialysate was observed. However, postdialysis systolic BP tended to be lower during hyponatremic treatment as compared to isonatremic dialysate $(-11.7 \mathrm{mmHg}$; $95 \% \mathrm{CI}-24.7$ to 1.4]). Ultrafiltration and antihypertensive treatment remained unchanged. 
Table 1. Baseline characteristics of the study population.

\begin{tabular}{cc}
\hline Characteristic & Cohort (n=11) \\
\hline Age (years) & $70.1 \pm 15.4$ \\
Male sex & $7(64 \%)$ \\
Ethnicity & \\
Caucasian & $10(91 \%)$ \\
African & $1(9 \%)$ \\
Vintage (months) & $52 \pm 47.25$ \\
Diabetes mellitus & $0(0 \%)$ \\
LVH & $7(70 \%)$ \\
Diastolic heart failure & $8(89 \%)$ \\
Antihypertensive drugs (N) & $3.1 \pm 1.5$ \\
Type antihypertensive drug & \\
ACEI or ARB & $8(73 \%)$ \\
CCB & $9(82 \%)$ \\
Beta-blocker & $6(54 \%)$ \\
Diuretic & $4(36 \%)$ \\
Moxonidine & $7(64 \%)$ \\
ESAs & $10(91 \%)$ \\
\hline
\end{tabular}

Values for categorical variables are given as number (percentage); values for continuous variables are given as mean \pm standard deviation except for vintage, were median \pm interquartile range is given. Abbreviations: ACEI, angiotensin-converting enzyme inhibitor; ARB, angiotensin receptor blocker; CCB, calcium channel blocker; ESAs, erythropoiesis stimulating agents; IDH, intradialytic hypertension; LVH, left ventricle hypertrophy.

Table 2. Mean intradialytic blood pressure $(\mathrm{mm} \mathrm{Hg})$ during week 4 of run-in, isonatremic and hyponatremic dialysis $(\mathrm{n}=11)$.

\begin{tabular}{|c|c|c|c|c|c|c|}
\hline & \multirow{2}{*}{$\begin{array}{c}\text { Run-in } \\
\text { Mean } \pm \text { SD }\end{array}$} & \multicolumn{2}{|c|}{ Isonatremic } & \multicolumn{3}{|c|}{ Hyponatremic } \\
\hline & & Mean \pm SD & $P_{1}$ & Mean \pm SD & $\mathrm{P}_{2}$ & $P_{3}$ \\
\hline \multicolumn{7}{|c|}{ Systolic blood pressure (mm Hg) } \\
\hline Predialysis & $158.0 \pm 18.3$ & $148.3 \pm 24.7$ & 0.04 & $144.4 \pm 16.5$ & 0.007 & 0.53 \\
\hline Postdialysis & $159.1 \pm 21.6$ & $154.2 \pm 25.5$ & 0.48 & $142.5 \pm 20.7$ & 0.01 & 0.07 \\
\hline Delta BP & $1.0 \pm 17.8$ & $6.0 \pm 18.8$ & 0.34 & $-1.9 \pm 23.2$ & 0.60 & 0.24 \\
\hline \multicolumn{7}{|c|}{ Diastolic blood pressure ( $\mathrm{mm} \mathrm{Hg}$ ) } \\
\hline Predialysis & $75.6 \pm 11.4$ & $67.7 \pm 12.0$ & 0.004 & $68.8 \pm 13.3$ & 0.036 & 0.63 \\
\hline Postdialysis & $80.3 \pm 12.1$ & $76.6 \pm 14.1$ & 0.21 & $73.0 \pm 12.9$ & 0.035 & 0.12 \\
\hline Delta BP & $4.7 \pm 7.4$ & $8.9 \pm 8.1$ & 0.17 & $4.2 \pm 8.5$ & 0.80 & 0.14 \\
\hline \multicolumn{7}{|c|}{ Interdialytic weight gain (kg), UF (kg) and number of antihypertensive drugs } \\
\hline Mean IDWG & $1.46 \pm 0.85$ & $1.61 \pm 0.98$ & 0.37 & $1.46 \pm 0.82$ & 0.97 & 0.39 \\
\hline Mean UF & $1.52 \pm 0.91$ & $1.52 \pm 0.86$ & 0.98 & $1.38 \pm 0.79$ & 0.39 & 0.30 \\
\hline AHT drugs $(\mathrm{N})$ & $3.1 \pm 1.5$ & $3.1 \pm 1.5$ & * & $3.1 \pm 1.5$ & * & * \\
\hline
\end{tabular}

Results are given as the mean \pm standard deviation at week 4 of each specific treatment period. Mean was calculated using measurements recorded during 3 hemodialysis sessions in the $4^{\text {th }}$ week of each treatment period. Delta BP reflects the blood pressure change from pre- tot postdialysis (i.e. postdialysis minus predialysis). $P_{1}$ reflects the level of significance comparing isonatremic to run-in values, using paired t-tests. $P_{2}$ reflects the level of significance comparing hyponatremic to run-in values, using paired t-tests. $\mathrm{P}_{3}$ reflects the level of significance comparing hyponatremic to isonatremic values, using paired t-tests. Abbreviations: AHT, antihypertensive; BP, blood pressure; IDWG, interdialytic weight gain; SD, standard deviation; UF, ultrafiltration. 


\subsection{4-Hour Ambulatory Blood Pressure Monitoring}

Hyponatremic dialysate was associated with a 9 to $10 \mathrm{mmHg}$ reduction in mean $24 \mathrm{~h}$ systolic and 3 to $4 \mathrm{mmHg}$ reduction in mean $24 \mathrm{~h}$ diastolic BP as compared to standard and isonatremic dialysate. These differences were apparent both during day and night time but did not attain statistical significance. Hypo- and isonatremic dialysate significantly improved daytime diastolic BP as compared to the standard dialysate (Table 3 ).

\subsection{Sodium and Sodium Gradient}

Mean DNa was $140 \pm 0.0 \mathrm{mEq} / \mathrm{l}$ during run-in, $139.4 \pm 2.4 \mathrm{mEq} / \mathrm{l}$ (range 135 $142 \mathrm{mEq} / \mathrm{l}$ ) during isonatremic and $136.4 \pm 1.6 \mathrm{mEq} / \mathrm{l}$ (range $133-138 \mathrm{mEq} / \mathrm{l}$ ) during hyponatremic treatment.

Based on the prior determined individual sodium set point, this corresponded to a mean dialysate-to-serum sodium gradient of respectively $0.3 \pm 2.8$ (run-in), $-0.3 \pm 0.9$ (isonatremic) and $-3.3 \pm 1.6 \mathrm{mEq} / \mathrm{L}$ (hyponatremic).

Predialysis serum sodium concentration did not change significantly during the 4 weeks of standard and isonatremic dialysis (Figure 2). During hyponatremic dialysis, mean predialysis serum sodium level decreased significantly

Table 3. Mean $24 \mathrm{~h}$ Ambulatory blood pressure ( $\mathrm{mm} \mathrm{Hg}$ ) during run-in, isonatremic and hyponatremic treatment $(\mathrm{n}=10)$.

\begin{tabular}{|c|c|c|c|c|c|c|}
\hline & \multirow{2}{*}{$\begin{array}{c}\text { Run-in } \\
\text { Mean } \pm S D\end{array}$} & \multicolumn{2}{|c|}{ Isonatremic } & \multicolumn{3}{|c|}{ Hyponatremic } \\
\hline & & Mean \pm SD & $\mathrm{P}_{1}$ & Mean \pm SD & $\mathrm{P}_{2}$ & $\mathrm{P}_{3}$ \\
\hline \multicolumn{7}{|c|}{ Mean $24 \mathrm{~h} \mathrm{BP}(\mathrm{mm} \mathrm{Hg})$} \\
\hline $24 \mathrm{~h} \mathrm{SBP}$ & $143.7 \pm 20.8$ & $143.5 \pm 28.0$ & 0.96 & $134.2 \pm 33.3$ & 0.10 & 0.09 \\
\hline $24 \mathrm{~h} \mathrm{DBP}$ & $75.1 \pm 10.9$ & $73.7 \pm 11.7$ & 0.19 & $70.8 \pm 14.5$ & 0.046 & 0.12 \\
\hline \multicolumn{7}{|c|}{ Mean day BP $(\mathrm{mm} \mathrm{Hg})$} \\
\hline Day SBP & $148.5 \pm 18.3$ & $147 \pm 26.8$ & 0.72 & $138.5 \pm 31.3$ & 0.09 & 0.15 \\
\hline Day DBP & $78.5 \pm 10.4$ & $76.0 \pm 10.9$ & 0.05 & $73.9 \pm 14.3$ & 0.047 & 0.29 \\
\hline \multicolumn{7}{|c|}{ Mean night $\mathrm{BP}(\mathrm{mm} \mathrm{Hg})$} \\
\hline Night SBP & $131.9 \pm 28.8$ & $138.9 \pm 38.9$ & 0.29 & $127.3 \pm 38.3$ & 0.37 & 0.054 \\
\hline Night DBP & $67.6 \pm 13.2$ & $69.9 \pm 16.0$ & 0.24 & $65.2 \pm 15.8$ & 0.14 & 0.08 \\
\hline \multicolumn{7}{|c|}{ Mean \% dipping } \\
\hline SBP dipping & $11.9 \pm 9.6$ & $6.2 \pm 12.2$ & 0.08 & $9.0 \pm 8.6$ & 0.14 & 0.37 \\
\hline DBP dipping & $14.3 \pm 7.8$ & $8.6 \pm 10.0$ & 0.02 & $12.2 \pm 7.0$ & 0.17 & 0.18 \\
\hline
\end{tabular}

Results of $24 \mathrm{~h}$ ambulatory blood pressure monitoring, performed after midweek dialysis session at week 4 of each treatment period, are shown as mean \pm standard deviation. Results are available for 10/11 patients, since one patient refused further $24 \mathrm{~h}$ ABPM after the first one. Dipping reflects relative blood pressure change from day to night, calculated as $(1-$ night $\mathrm{BP} /$ day $\mathrm{BP}) \times 100$. Day and night hours are based on patient-reported sleeping and awakening hours. $P_{1}$ reflects the level of significance comparing isonatremic to run-in values, using paired t-tests. $\mathrm{P}_{2}$ reflects the level of significance comparing hyponatremic to run-in values, using paired t-tests. $\mathrm{P}_{3}$ reflects the level of significance comparing hyponatremic to isonatremic values, using paired t-tests. Abbreviations: BP, blood pressure; DBP, diastolic blood pressure; SBP, systolic blood pressure; $24 \mathrm{~h}, 24$ hours. 
Evolution of serum sodium during iso- and hyponatremic treatment

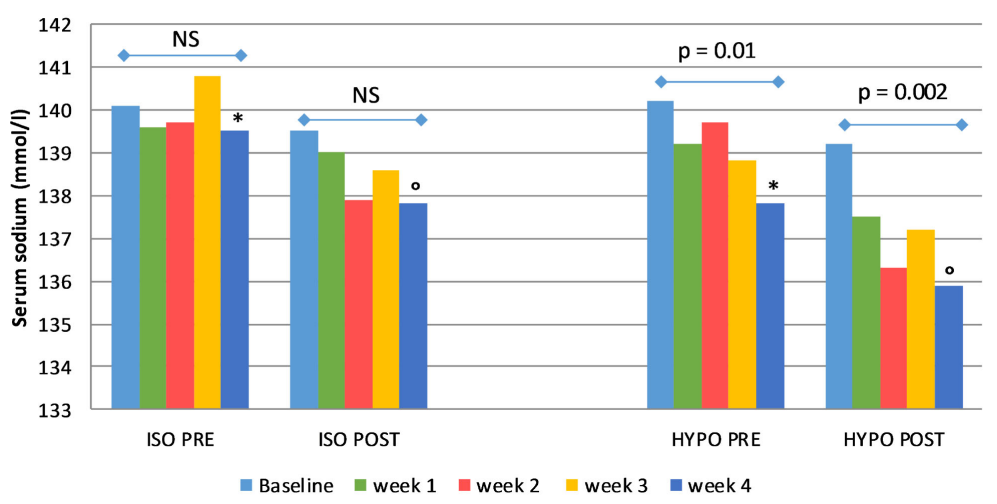

Figure 2. Evolution of serum sodium levels during iso- and hyponatremic treatment. Mean pre- and postdialysis serum sodium levels were determined at midweek dialysis sessions. "Baseline" reflects the mean serum sodium level just before starting resp. iso- or hyponatremic $\mathrm{DNa}$ • baseline. ${ }^{\star} \mathrm{p}<0.05$, comparing iso- to hyponatremic predialysis serum sodium concentration. ${ }^{\circ} \mathrm{p}<0.005$, comparing iso- to hyponatremic postdialysis serum sodium concentration. Abbreviations: DNa, dialysate sodium concentration; HYPO POST, hyponatremic postdialysis; HYPO PRE, hyponatremic predialysis;ISO POST, isonatremic postdialysis; ISO PRE, isonatremic predialysis; NS, not significant.

from $140.2 \mathrm{mEq} / \mathrm{L}$ at baseline to $137.8 \mathrm{mEq} / \mathrm{L}$ at week $4(\mathrm{p}=0.01)$, and mean postdialysis serum sodium level from $139.1 \mathrm{mEq} / \mathrm{L}$ at baseline to $135.9 \mathrm{mEq} / \mathrm{L}$ at week $4(\mathrm{p}=0.002)$. At the end of the hyponatremic treatment period, both preand postdialysis serum sodium were significantly lower, compared to values at the end of isonatremic treatment period $(\mathrm{p}<0.05)$.

\subsection{Renin, Aldosterone and Catecholamines}

Overall, renin and aldosterone showed similar intradialytic patterns over different treatment periods (Supplementary Table S1). Aldosterone levels decreased significantly from pre- to postdialysis whereas no significant change was observed in renin. We did not observe significant differences in pre- and post-dialysis levels between treatment periods.

A small significant rise of norepinephrine from pre- to postdialysis was observed in run-in, but not during iso- or hyponatremic treatment. Dopamine and epinephrine showed no intradialytic change.

\subsection{Interdialytic Weight Gain}

No significant change in interdialytic weight gain was observed (Table 2), while dry weight was kept constant. Pre- and postdialysis NT-proBNP showed no significant difference between treatment periods.

\subsection{Safety Profile}

Overall, all DNa concentrations were well tolerated. Adverse events occurred in 
8/132 (6\%), 11/132 (8\%) and 12/132 (9\%) dialysis sessions during resp. run-in, isonatremic and hyponatremic treatment. Symptomatic hypotension occurred most frequently during isonatremic dialysis (4/132) compared to standard DNa and hyponatremic HD (both 1/132). Muscle cramps were more frequent during isonatremic (6/132) and hyponatremic (8/132) treatment compared to run-in (2/132). Two patients were hospitalized: one for pneumonia during the wash-out period; one for symptomatic sick sinus syndrome during the hyponatremic period.

\section{Discussion}

This trial investigated the hypothesis that individualized $\mathrm{DNa}$ would, by reducing sodium loading, improve both intradialytic and interdialytic BP and thus decrease the global BP burden in patients with a history of IDH.

While no changes in antihypertensive drug regimen and in target dry weight were allowed during the study, we did observe a marked improvement in overall BP control. Both pre- and postdialysis systolic and diastolic BPs decreased when standard dialysate was changed to isonatremic or hyponatremic dialysate. The mean reductions of $13 \mathrm{mmHg}$ in predialysis and $16 \mathrm{mmHg}$ in postdialysis systolic $\mathrm{BP}$ in passing from standard $\mathrm{DNa}$ to hyponatremic dialysate were both clinically and statistically significant. In addition, hyponatremic dialysate was associated with a $9-10 \mathrm{mmHg}$ mean reduction in $24 \mathrm{~h}$ ambulatory SBP and $3-4$ mmHg mean reduction in $24 \mathrm{~h}$ ambulatory DBP, without reaching statistical significance. However, the magnitude of this BP lowering is clearly clinically relevant and in line with the marked reductions in predialysis "office" BP.

Previous studies in general HD populations have shown variable effects of dialysate sodium lowering on BP. Some studies showed a decrease in predialysis SBP after a facility-based reduction of $\mathrm{DNa}$ [15], while others didn't [16]. In most studies, a uniform reduction in $\mathrm{DNa}$ was performed, regardless of individual serum sodium levels.

Despite the small sample size, our observations provide some compelling evidence on the efficacy of an individually lowered DNa, to improve BP control in patients with IDH. This effect on BP doesn't seem to be volume-related, since dry weight was kept constant and IDWG did not change significantly. However, it is known that high sodium levels can influence BP regardless of volume-related effects. In a small prospective cross-over study in chronic HD patients, lowering $\mathrm{DNa}$ by $5 \mathrm{mEq} / \mathrm{L}$ without extra fluid removal had a beneficial effect on interdialytic $48 \mathrm{~h} \mathrm{BP}$, by reducing systemic vascular resistance index [17]. Others described endothelial cell dysfunction with acute stiffening and decreased release of nitric oxide after exposure to higher sodium concentrations [8]. Lower DNa may also influence the storage capacity for "osmotic inactive" sodium, creating a greater hemodynamic buffering capacity [18].

Despite the marked effect on overall BP control, individually tailoring the dialysate sodium concentration did not completely mitigate the intradialytic blood pressure rise. This might suggest that other mechanisms play a pathophysiologi- 
cal role in IDH. Previous studies have indeed demonstrated endothelial cell dysfunction with inappropriate increase of vasoconstrictors such as endothelin in subjects with IDH [4]. We only studied the effect on catecholamines and RAAS and didn't observe any pattern changes. This doesn't entirely exclude increased sympathetic nervous system activity, as plasma catecholamines are only indirect markers of sympathetic activity.

To our best knowledge, this is the first prospective interventional trial evaluating the effects of individualized iso- and hyponatremic dialysate on both "office" and ambulatory BP in a cohort of patients with known IDH. An additional strength of our study is the relatively long duration of treatment periods, with a wash-out period between the randomly allocated use of isonatremic and hyponatremic dialysate. Indeed, it is known that BP lowering interventions can be prone to a lag-time phenomenon, with BP changes occurring several weeks after the intervention [19]. With our longer follow-up and wash-out period, we intended to avoid this potential bias and the potential carry-over effects between study periods.

The present study has some limitations too. First, the small sample size provides only limited statistical power to precisely estimate treatment effects. Lack of power may be the reason why the marked absolute reductions in ambulatory BP did not attain statistical significance. Another limitation is the use of an estimated sodium gradient. We did not measure delivered dialysate sodium, but used the dialyzer set-up tool instead. The latter has been presented as a valid alternative for the truly measured sodium gradient [20], but remains an approximation. Also for reasons of clinical applicability, we didn't take the Gibbs-Donnan effect into account, although this influences the net sodium gradient as well [21].

The small difference in dialysate-to-serum sodium gradient between iso- and hyponatremic dialysis could be seen as another shortcoming. Inrig et al. reported significant BP changes with higher gradients during a one-week-treatment (gradient $+5 \mathrm{mEq} / \mathrm{L}$ vs $-2.9 \mathrm{mEq} / \mathrm{L}$ ) [12]. On the other hand, it has been shown that both predialysis hypo- and hypernatremia carry short-term risk [22]. Because of safety concerns, we opted for smaller differences in sodium gradient with compensatory longer treatment periods. A last limitation might be the lack of evaluating dietary sodium intake. However, the random allocation of treatment periods should have attenuated this bias due to temporal fluctuations in diet.

The ideal DNa remains controversial [23]. In a general HD population, dialyzing with lower sodium concentrations has been reported as a safe technique [7]. On the other hand, observational data described an association between lower DNa and adverse outcomes, especially for subjects with lower serum sodium level [24]. In a review by Basile et al., authors state that with incongruent evidence, no definite conclusion on the superiority of either low or high dialysate sodium can be drawn [25]. In our study, mean predialysis sodium serum concentrations decreased by $2 \mathrm{mEq} / \mathrm{L}$ after 1 month of hyponatremic dialysate treatment. It's unclear if this was due to a factual change of the serum sodium set point, or due to fluid overload with a dilution effect, since dry weight was not 
changed. However, the safety of long-term use (beyond 4 weeks) of hyponatremic dialysate remains unclear.

In this randomized cross-over study of iso- and hyponatremic dialysate in patients with IDH, a marked reduction in intra-and interdialytic systolic and diastolic BP is observed compared to dialysis with a standard DNa of $140 \mathrm{mEq} / \mathrm{L}$. The current study also provides some evidence that individualized hyponatremic dialysate can safely be used in patients prone to intradialytic hypertension. It is an inexpensive and easy-to-use method to obtain better BP control in these patients. Moreover, these data should encourage investigators to conduct further research on the use of hyponatremic dialysate in a long-term prospective and randomized parallel group study, as the long-term effects and safety remain unknown.

\section{Acknowledgements}

The authors thank the nursing staff of the dialysis unit for their assistance; and Ms Nathalie Marmitte and Ms Nadia Fenners for administrative assistance.

\section{Support}

This research was funded by the nephrology department of the Universitair Ziekenhuis Brussel.

PVDN contributed to the conception, design, collection, analysis and interpretation of the data, article drafting and revision. TR was responsible for data collection, analysis and interpretation, article drafting and revision. MA and XG helped in data collection and article revision. KMW helped in interpretation of the data and article revision. All authors provided intellectual content of critical importance, reviewed and approved the version to be published.

\section{Conflicts of Interest}

The authors declare no conflicts of interest regarding the publication of this paper.

\section{References}

[1] Inrig, J.K., Oddone, E.Z., Hasselblad, V., et al. (2007) Association of Intradialytic Blood Pressure Changes with Hospitalization and Mortality Rates in Prevalent ESRD Patients. Kidney International, 71, 454-461. https://doi.org/10.1038/sj.ki.5002077

[2] Van Buren, P.N. (2017) Pathophysiology and Implications of Intradialytic Hypertension. Current Opinion in Nephrology and Hypertension, 26, 303-310. https://doi.org/10.1097/MNH.0000000000000334

[3] Van Buren, P.N., Zhou, Y., Neyra, J.A., et al. (2016) Extracellular Volume Overload and Increased Vasoconstriction in Patients with Recurrent Intradialytic Hypertension. Kidney and Blood Pressure Research, 41, 802-814. https://doi.org/10.1159/000450565

[4] Chou, K.J., Lee, P.T., Chen, C.L., et al. (2006) Physiological Changes during Hemo- 
dialysis in Patients with Intradialysis Hypertension. Kidney International, 69, 1833-1838. https://doi.org/10.1038/sj.ki.5000266

[5] Basile, C. and Lomonte, C. (2015) A Neglected Issue in Dialysis Practice: Haemodialysate. Clinical Kidney Journal, 8, 393-399. https://doi.org/10.1093/ckj/sfv038

[6] Inrig, J.K. (2010) Intradialytic Hypertension: A Less-Recognized Cardiovascular Complication of Hemodialysis. American Journal of Kidney Diseases, 55, 580-589. https://doi.org/10.1053/j.ajkd.2009.08.013

[7] Munoz Mendoza, J., Sun, S., Chertow, G.M., Moran, J., Doss, S. and Schiller, B. (2011) Dialysate Sodium and Sodium Gradient in Maintenance Hemodialysis: A Neglected Sodium Restriction Approach? Nephrology Dialysis Transplantation, 26, 1281-1287. https://doi.org/10.1093/ndt/gfq807

[8] Oberleithner, H., Riethmüller, C., Schillers, H., MacGregor, G.A., de Wardener, H.E. and Hausberg, M. (2007) Plasma Sodium Stiffens Vascular Endothelium and Reduces Nitric Oxide Release. Proceedings of the National Academy of Sciences of the United States of America, 104, 16281-16286. https://doi.org/10.1073/pnas.0707791104

[9] Guyenet, P.G. (2006) The Sympathetic Control of Blood Pressure. Nature Reviews Neuroscience, 7, 335-346. https://doi.org/10.1038/nrn1902

[10] Gu, J.W., Anand, V., Shek, E.W., et al. (1998) Sodium Induces Hypertrophy of Cultured Myocardial Myoblasts and Vascular Smooth Muscle Cells. Hypertension, 31, 1083-1087. https://doi.org/10.1161/01.HYP.31.5.1083

[11] Movilli, E., Camerini, C., Gaggia, P., et al. (2013) Role of Dialysis Sodium Gradient on Intradialytic Hypertension: An Observational Study. American Journal of Nephrology, 38, 413-419. https://doi.org/10.1159/000355974

[12] Inrig, J.K., Molina, C., D’Silva, K., et al. (2015) Effect of Low versus High Dialysate Sodium Concentration on Blood Pressure and Endothelial-Derived Vasoregulators during Hemodialysis: a Randomized Crossover Study. American Journal of Kidney Diseases, 65, 464-473. https://doi.org/10.1053/j.ajkd.2014.10.021

[13] National Kidney Foundation (2015) KDOQI Clinical Practice Guideline for Hemodialysis Adequacy: 2015 Update. American Journal of Kidney Diseases, 66, 884-930. https://doi.org/10.1053/j.ajkd.2015.07.015

[14] Peixoto, A.J., Gowda, N., Parikh, C.R. and Santos, S.F. (2010) Long-Term Stability of Serum Sodium in Hemodialysis Patients. Blood Purification, 29, 264-267. https://doi.org/10.1159/000274460

[15] Thein, H., Haloob, I. and Marshall, M.R. (2007) Associations of a Facility Level Decrease in Dialysate Sodium Concentration with Blood Pressure and Interdialytic Weight Gain. Nephrology Dialysis Transplantation, 22, 2630-2639. https://doi.org/10.1093/ndt/gfm220

[16] Aybal Kutlugün, A., Erdem, Y., Okutucu, S., Yorgun, H., Atalar, E. and Arici, M. (2011) Effects of Lowering Dialysate Sodium on Flow-Mediated Dilatation in Patients with Chronic Kidney Disease. Nephrology Dialysis Transplantation, 26, 3678-3682. https://doi.org/10.1093/ndt/gfr092

[17] Farmer, C.K.T., Donohoe, P., Dallyn, P., Cox, J., Kingswood, J. and Goldsmith, D. (2000) Low-Sodium Haemodialysis without Fluid Removal Improves Blood Pressure Control in Chronic Haemodialysis Patients. Nephrology, 5, 237-241. https://doi.org/10.1046/j.1440-1797.2000.00004.x

[18] Titze, J., Luft, F.C., Bauer, K., et al. (2006) Extrarenal $\mathrm{Na}^{+}$Balance, Volume, and Blood Pressure Homeostasis in Intact and Ovariectomized Deoxycorticosterone-Acetate Salt Rats. Hypertension, 47, 1101-1107. 
https://doi.org/10.1161/01.HYP.0000221039.17735.1a

[19] Charra, B., Bergström, J. and Scribner, B.H. (1998) Blood Pressure Control in Dialysis Patients: Importance of the Lag Phenomenon. American Journal of Kidney Diseases, 32, 720-724. https://doi.org/10.1016/S0272-6386(98)70147-7

[20] Santos, S.F. and Peixoto, A.J. (2008) Revisiting the Dialysate Sodium Prescription as a Tool for Better Blood Pressure and Interdialytic Weight Gain Management in Hemodialysis Patients. Clinical Journal of the American Society of Nephrology, 3, 522-530. https://doi.org/10.2215/CJN.03360807

[21] Hanafusa, N., Tsuchiya, K. and Nitta, K. (2018) Dialysate Sodium Concentration: The Forgotten Salt Shaker. Seminars in Dialysis, 31, 563-568. https://doi.org/10.1111/sdi.12749

[22] Rhee, C.M., Ravel, V.A., Ayus, J.C., et al. (2016) Pre-Dialysis Serum Sodium and Mortality in a National Incident Hemodialysis Cohort. Nephrology Dialysis Transplantation, 31, 992-1001. https://doi.org/10.1093/ndt/gfv341

[23] Dunlop, J.L., Vandal, A.C. and Marshall, M.R. (2019) Low Dialysate Sodium Levels for Chronic Haemodialysis. Cochrane Database of Systematic Reviews, 1, CD011204. https://doi.org/10.1002/14651858.CD011204.pub2

[24] Hecking, M., Karaboyas, A., Saran, R., et al. (2012) Dialysate Sodium Concentration and the Association with Interdialytic Weight Gain, Hospitalization, and Mortality. Clinical Journal of the American Society of Nephrology, 7, 92-100. https://doi.org/10.2215/CJN.05440611

[25] Basile, C., Pisano, A., Lisi, P., Rossi, L., Lomonte, C. and Bolignano, D. (2016) High versus Low Dialysate Sodium Concentration in Chronic Haemodialysis Patients: A Systematic Review of 23 Studies. Nephrology Dialysis Transplantation, 31, 548-563. https://doi.org/10.1093/ndt/gfv084 


\section{Supplementary Data}

Table S1. Catecholamines, renin and aldosterone after different treatment periods $(\mathrm{n}=$ 11).

\begin{tabular}{|c|c|c|c|}
\hline & Run-in & Isonatremic & Hyponatremic \\
\hline \multicolumn{4}{|c|}{ Norepinephrine $(\mu \mathrm{g} / \mathrm{l})$} \\
\hline Predialysis & $0.48 \pm 0.25$ & $0.51 \pm 0.44$ & $0.52 \pm 0.21$ \\
\hline Postdialysis & $0.66 \pm 0.36$ & $0.70 \pm 0.74$ & $0.64 \pm 0.23$ \\
\hline $\mathrm{P}$-value & 0.04 & 0.15 & 0.20 \\
\hline \multicolumn{4}{|c|}{ Epinephrine $(\mu \mathrm{g} / \mathrm{l})$} \\
\hline Predialysis & $0.05 \pm 0.02$ & $0.06 \pm 0.02$ & $0.04 \pm 0.01$ \\
\hline Postdialysis & $0.05 \pm 0.02$ & $0.07 \pm 0.04$ & $0.05 \pm 0.02$ \\
\hline $\mathrm{P}$-value & 0.83 & 0.26 & 0.49 \\
\hline \multicolumn{4}{|c|}{ Dopamine $(\mu \mathrm{g} / \mathrm{l})$} \\
\hline Predialysis & $0.10 \pm 0.00$ & $0.10 \pm 0.00$ & $0.10 \pm 0.00$ \\
\hline Postdialysis & $0.10 \pm 0.00$ & $0.12 \pm 0.06$ & $0.11 \pm 0.02$ \\
\hline $\mathrm{P}$-value & NA & 0.34 & 0.34 \\
\hline \multicolumn{4}{|c|}{ Active renin (ng/l) } \\
\hline Predialysis & $15.9 \pm 24.5$ & $13.8 \pm 13.7$ & $18.5 \pm 19.3$ \\
\hline Postdialysis & $19.2 \pm 38.9$ & $13.3 \pm 12.2$ & $23.6 \pm 37.4$ \\
\hline $\mathrm{P}$-value & 0.50 & 0.74 & 0.42 \\
\hline \multicolumn{4}{|c|}{ Aldosterone (ng/l) } \\
\hline Predialysis & $132.2 \pm 76.9$ & $178.9 \pm 138.6$ & $254.2 \pm 264.1$ \\
\hline Postdialysis & $59.5 \pm 19.2$ & $79.0 \pm 81.0$ & $128.5 \pm 146.8$ \\
\hline $\mathrm{P}$-value & 0.004 & 0.01 & 0.02 \\
\hline \multicolumn{4}{|c|}{ Potassium (mEq/1) } \\
\hline Predialysis & $5.2 \pm 0.7$ & $5.1 \pm 0.8$ & $4.8 \pm 0.6$ \\
\hline Postdialysis & $3.8 \pm 0.3$ & $3.5 \pm 0.6$ & $3.5 \pm 0.5$ \\
\hline P-value & $<0.0001$ & $<0.0001$ & 0.0002 \\
\hline \multicolumn{4}{|c|}{ NT-ProBNP (ng/l) } \\
\hline Predialysis & $2552 \pm 3865$ & $3394 \pm 5912$ & $2276 \pm 2902$ \\
\hline Postdialysis & $1371 \pm 1802$ & $2249 \pm 3390$ & $1346 \pm 1468$ \\
\hline P-value & 0.09 & 0.08 & 0.06 \\
\hline
\end{tabular}

Data are shown as mean \pm standard deviation. Blood samples were obtained at midweek of the $4^{\text {th }}$ week of each treatment period. P-value shows significance level for comparison of pre- to postdialysis values, using paired t-test. Paired t-test comparing values of iso- to hyponatremic treatment, showed no significant difference. Abbreviations: NA, not available. 